\title{
Peritoneal encapsulation, left paraduodenal hernia with retroperitonealization of inferior mesenteric vein leading to triple obstruction
}

\author{
Imtiaz Wani, Khursheed A Wani, Muneer Wani, Gulzar Bhat, \\ Mubashir Shah
}

\begin{abstract}
Introduction: Encasing of small bowel in an anomalous accessory membrane results in peritoneal encapsulation and is a very rare cause of intestinal obstruction. It is believed to be caused by malrotation of the bowel during the 12th week of gestation and this causes the formation of an accessory sac from the peritoneum, covering the umbilicus. Left paraduodenal hernia is the most common form of congenital internal hernia. Paraduodenal hernia are caused by abnormal rotation of the midgut during embryonic development. This rarely presents as an intestinal obstruction. Congenital adhesions are rare in adults and these may lead to retroperitonealization of inferior mesenteric vein (IMV). Case Report: A case of peritoneal encapsulation and left paraduodenal hernia with congenital adhesions leading to retroperitonealization of inferior mesenteric vein (IMV) in the same patient is reported here. A 28 -year-old male presented with recurrent small bowel obstruction and was diagnosed with an intestinal obstruction. Computed tomography confirmed peritoneal encapsulation and left paraduodenal hernia with features of intestinal obstruction. Excision of membrane and reduction of hernia with retroperitonealization of inferior mesenteric
\end{abstract}

Imtiaz Wani ${ }^{1}$, Khursheed A Wani ${ }^{1}$, Muneer Wani ${ }^{1}$, Gulzar Bhat $^{1}$, Mubashir Shah ${ }^{1}$

Affiliations: ${ }^{1}$ Department of General Surgery, SKIMS, Srinagar, Kashmir, India.

Corresponding Author: Imtiaz Wani, Department of General Surgery, SKIMS, Srinagar, Kashmir, India 190009; Ph: 9419005169

Received: 17 August 2012

Accepted: 15 October 2012

Published: 01 March 2013 vein was done. Conclusion: This is the first case reported in literature where peritoneal encapsulation, paraduodenal hernia and retroperitonealization of inferior mesenteric vein (IMV) occurred together and lead to bowel obstruction. In this case, the origin of three abnormal anatomical structures must have been congenital as there was no history of prior surgery.

Keywords: Encapsulation, Paraduodenal, inferior mesenteric vein (IMV)

$$
* * * * * * * * *
$$

Wani I, Wani KA, Wani M, Bhat G, Shah M. Peritoneal encapsulation, left paraduodenal hernia with retroperitonealization of inferior mesenteric vein leading to triple obstruction. International Journal of Case Reports and Images 2013;4(3):169-174.

$$
* * * * * * * * *
$$

doi:10.5348/ijcri-2013-03-287-CR-8

\section{INTRODUCTION}

The peritoneal encapsulation, first described by Cleland [1] in 1868, is a rare developmental abnormality in which part or the entire small bowel is encased in an accessory sac. It is believed to be caused by malrotation of the bowel during the 12th week of gestation and this causes the formation of an accessory sac from the peritoneum covering the umbilicus [2]. The incidence of this condition is not well known. There are not more than 50 to 60 cases described in literature [3-5]. Most of the cases remain asymptomatic; diagnosed usually as an incidental finding during surgery for unrelated conditions and only rarely present as bowel obstruction [6-8]. Paraduodenal hernia is the most common type of intestinal hernia, accounting for $30-53 \%$ of all cases 
and accounts for $0.2-0.9 \%$ of all bowel obstructions [9]. This hernia has a variable clinical manifestation and rarely may present as an acute abdomen. In adults, occurrence of congenital bands is an extremely rare condition $[10,11]$. The entrapment of the intestine between the bands and the mesentery or by compression of the bowel leads to obstruction. Rarely a vessel with an abnormal position compressing on the gut could lead to bowel obstruction [3].

Clinical diagnosis of bowel obstruction is often difficult to make due to ambiguous presentation in peritoneal encapsulation, paraduodenal hernia, congenital bands and an abnormal vessel compressing the gut [12-14]. X-ray of abdomen, ultrasonography, barium study and computed tomography are contributory in diagnosis of each form of obstruction. The excision of membrane in peritoneal encapsulation is recommended even if this condition is diagnosed incidentally. All paraduodenal hernias must be repaired, including those that are asymptomatic [15]. Release of adhesions in congenital bands and the retroperitonealization of vessel leading to obstruction is recommended.

\section{CASE REPORT}

A 28-year-old male presented with generalized abdominal pain, fever and multiple episodes of vomiting. Abdominal pain was episodic and colicky and vomitus was bilious. There was no past history of trauma or surgery. Patient had a past history of three episodes of similar abdominal pain and vomiting three months back. Second episode occurred 12 days after the first episode and third episode occurred 21 days after first episode. Patient was diagnosed as a case of recurrent sub-acute intestinal obstruction by small gut stricture which was confirmed on the barium study at that time. During and after each episode the patient was managed conservatively without any surgical intervention. General physical examination during current episode showed dehydrated appearence, pulse $96 / \mathrm{min}$, blood pressure 110/70 $\mathrm{mmHg}$, and temperature of $99^{\circ} \mathrm{C}$. Systemic examination was normal. Abdominal examination revealed distended abdomen, diffuse tenderness and a high pitch bowel sounds. Laboratory parameters were normal. X-ray of abdomen showed multiple air fluid levels. Computed tomography scan of the abdomen revealed conglomeration of gut in a thin sac suggestive of peritoneal encapsulation on the right side. There was displacement of inferior mesenteric vein and the entrapped bowel in left upper abdomen (left paraduodenal hernia) (Figure 1A-B).Gut loops were dilated and had thick walls. Exploratory laparotomy revealed encasement of bowel loops in membrane, typical of peritoneal encapsulation with inter-loop adhesions present in the bowel outside the peritoneal sac (Figure 2). Gut inside peritoneal encapsulation was dilated, which was suggestive of obstruction. Malrotations of small gut loops was seen. After careful dissection of the membrane, adhesiolysis and release of omental adhesions, a vessel lying on ileal loops, outside the retroperitoneum, was seen which was identified as inferior mesenteric vein (IMV) (Figure 3A-B). The bowel proximal to the abnormally placed IMV was dilated with thickened wall which was suggestive of obstruction. This abnormally lying IMV was constrained by adhesions to small bowel. Peritoneal encapsulation and retroperitonealization of IMV were leading to sub-acute intestinal obstruction. Further exploration revealed a loop of intestine impacted in a left paraduodenal fossa. Diagnosis of the left paraduodenal hernia was confirmed (Figure 4A-B). Incarcerated segment of bowel in left paraduodenal fossa had signs of strangulation with thickened walls leading to acute abdomen. Resection of incarcerated segment and the closure of hernial orifice was done. Retroperitonealization of anteriorly placed IMV was achieved. Postoperative period was uneventful and patient was discharged after one week. Patient is well on follow up for last 13 months.

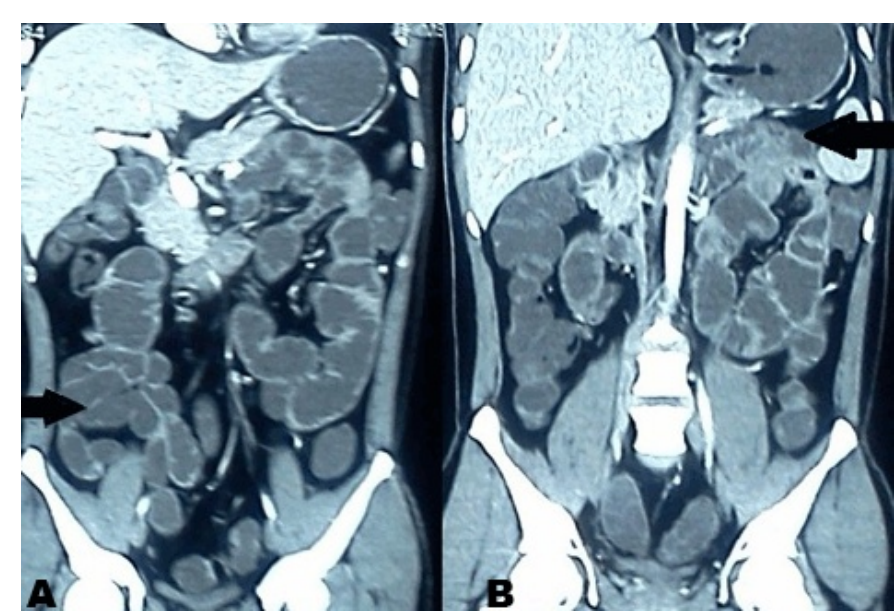

Figure 1(A, B): Computed tomography scan of the abdomen in axial and coronal cuts demonstrating left paraduodenal hernia. Arrows are outlining the hernial sac, with clustered, sharply circumscribed loops of small bowel in the left upper abdomen. In right lower abdomen gut loops conglomerated in peritoneal sac.

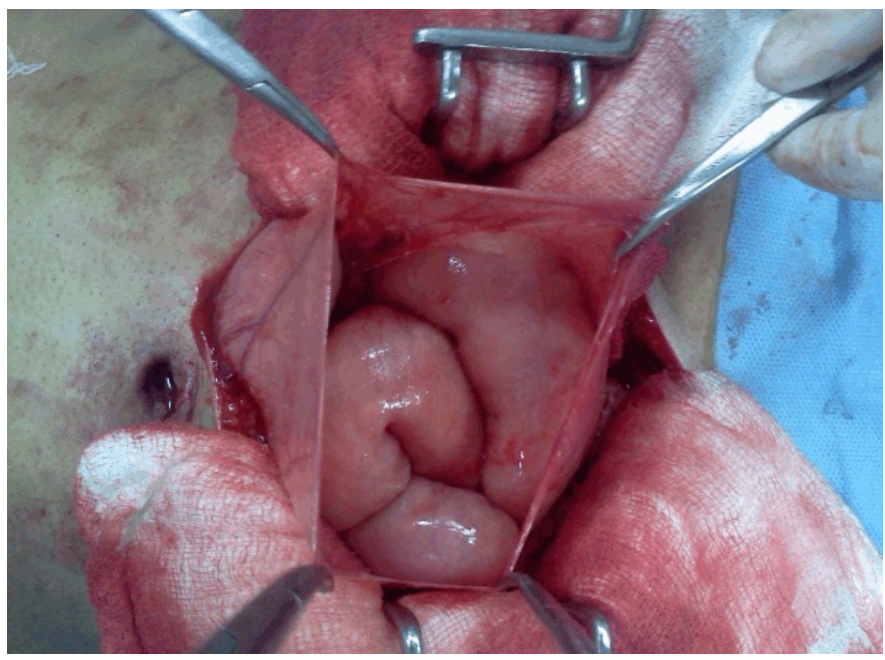

Figure 2: Bowel encased in a membrane suggestive of peritoneal encapsulation. 


\section{DISCUSSION}
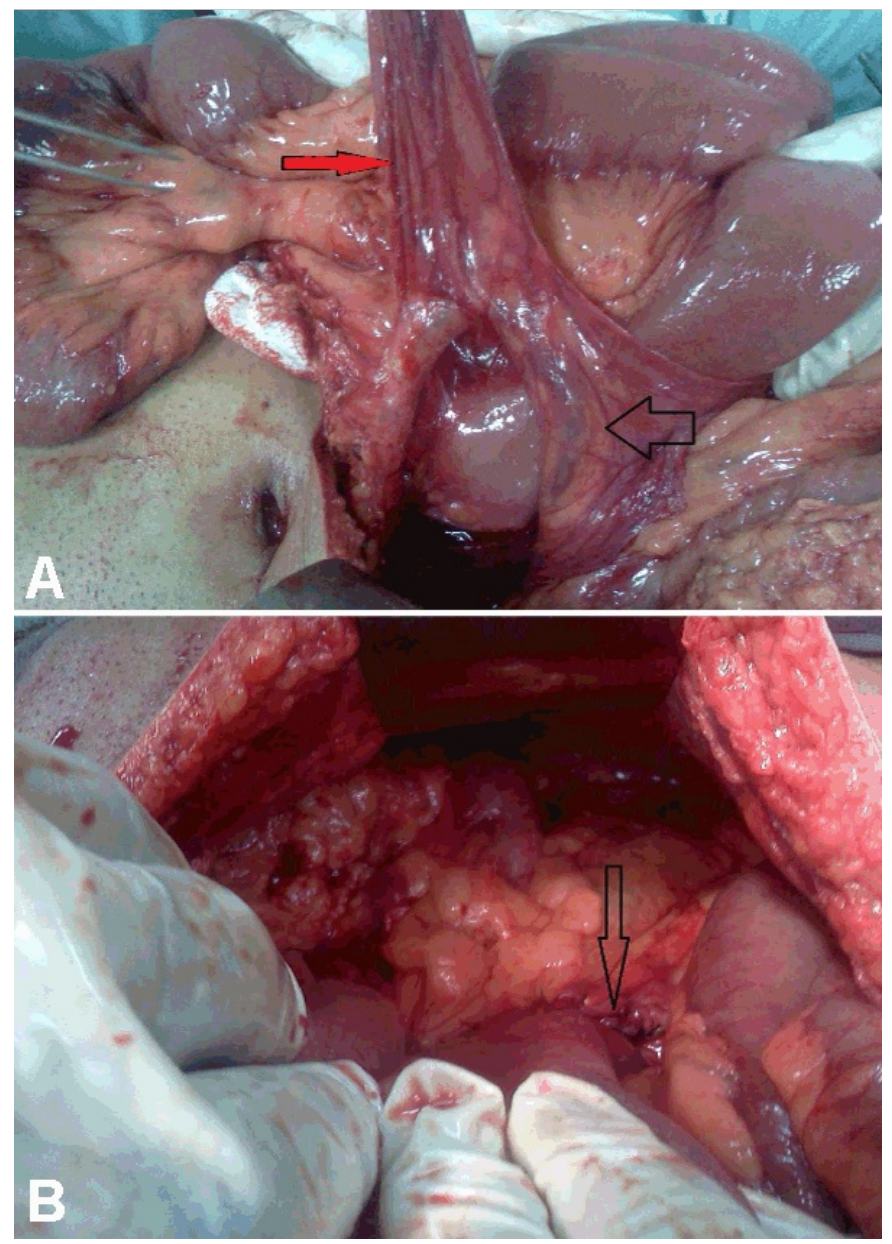

Figure 3(A, B): Gut loops compressed by inferior mesenteric vein lying in the retroperitoneum and site of retroperitonealisation of inferior mesenteric vein.
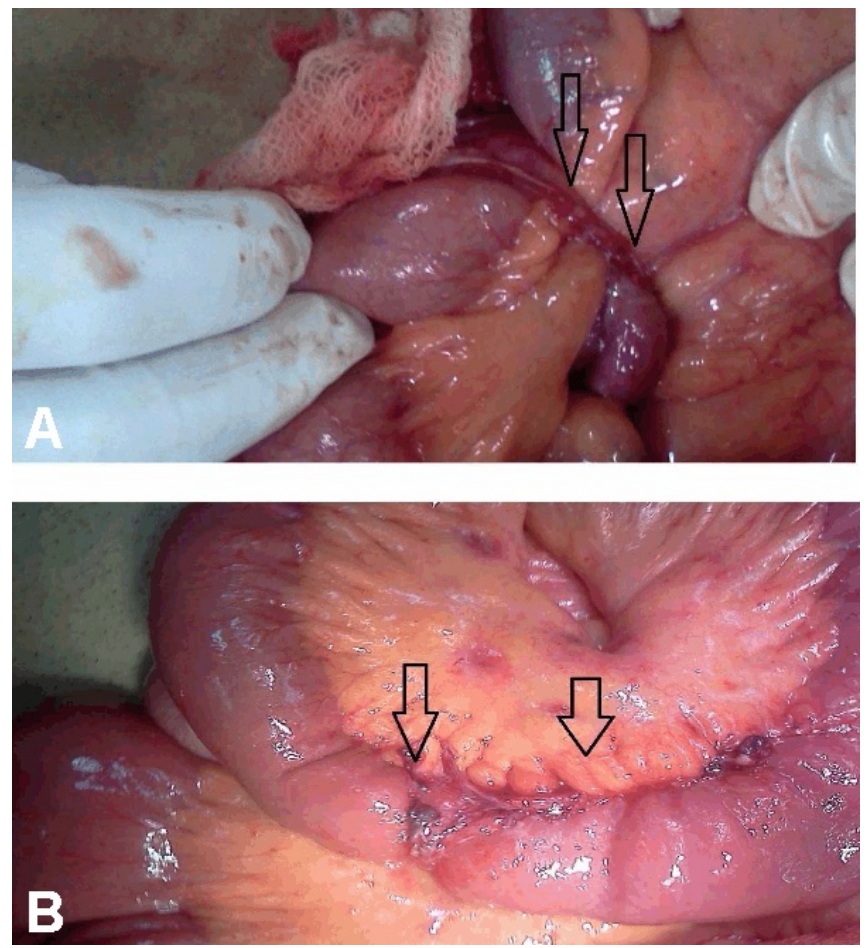

Figure 4(A, B): Left paraduodenal hernia impacted in paraduodenal fossa and the incarcerated gut (arrow).
Peritoneal encapsulation is a developmental abnormality encasing part or the entire small bowel in an accessory sac derived from the yolk sac [16]. The accessory peritoneal membrane is derived from the peritoneum of the yolk sac which withdraws into the abdominal cavity with the small bowel instead of remaining at the base of the umbilical cord. This is attached to the ascending and descending colon laterally, the transverse mesocolon superiorly and merges with posterior parietal peritoneum inferiorly. The membrane has two openings, one around the duodenojejunal flexure and the other at the ileocecal junction [7]. Peritoneal encapsulation seems to be predominant in males and is not always associated with abnormal intestinal rotation $[17,18]$. The condition is largely asymptomatic but some cases may present as bowel obstruction $[19,20]$. Peritoneal encapsulation very rarely leads to an acute iliac occlusion or to idiopathic sclerosing peritonitis [21, 22]. This congenital encapsulation can be diagnosed incidentally during laparotomy for other conditions and some cases are diagnosed at autopsy [3, 8]. It can occur with incomplete situs inversus and abnormal artery (both are congenital anomalies) or as an incidental findings at time of gastric surgery or during colon cancer surgery $[4,23]$.

Paraduodenal hernia is a rare condition in which the small bowel loops are trapped within a congenital paraduodenal fossa [24]. Males are three times more affected than females [25]. Paraduodenal hernia are divided into two subtypes: left or right paraduodenal hernia. About 75\% are located on the left side [9]. A case of congenital pyloric stenosis associated with the presence of a paraduodenal hernia in an adult patient has been reported [26]. Paraduodenal hernia lacks a true hernial sac and is termed 'prolapse' or 'procidentia' rather than a hernia [27 ]. The left paraduodenal hernia is a result of anomalous rotation of midgut into the developing mesentery of the descending colon with mechanical forces of fluctuating intra-abdominal pressure leading to herniation in places where the peritoneum is yet incompletely fused [27, 28]. They originate at the fossa of Landzert which is just lateral to the fourth segment of the duodenum and behind the inferior mesenteric vein and ascending left colic artery [29]. The sac lies to left of the duodenum. Inferior mesenteric vessels constitute the anterior free margin of the sac [30]. Accurate anatomy is important surgically, as the inferior border of the hernia opening is safest place to widen the neck of the hernia [27].

Symptoms of paraduodenal hernia are non-specific, ranging from recurrent vague abdominal pain, nausea, vomiting and reversible obstruction leading to an acute abdomen [31]. About 50\% cases follow an asymptomatic clinical course and are diagnosed incidentally; rest 50\% patients with paraduodenal hernia have episodes of intestinal obstruction at some point of their lives [32]. The symptoms depend on patient's position, with symptoms aggravating while standing and relieved in a 
supine position [33]. Spontaneous reduction apparently causes the periodic presentation of abdominal pain with normal radiographic studies [34]. The herniated small bowel loops may become trapped within this mesenteric sac. Symptoms may also result from retroperitoneal mass effect.

Adhesions are the cause of about $30-41 \%$ of all intestinal obstructions and for the small bowel obstruction, the proportion rises to $65-75 \%$ [35]. Only $3 \%$ of these are thought to be caused by congenital omental bands formed by abnormal adhesions of the peritoneal folds during embryogenesis [10, 36]. In our case, congenital adhesions might have led to constraining effect on IMV leading to its retroperitonealization which compressed the small bowel leading to obstruction. A congenital constraining of adhesions between the vein and the gut can also lead to bowel obstruction.

In view of the diagnostic difficulty based on clinical findings, imaging studies often play an important role in the diagnosis. Radiographic studies are usually normal or show non-specific features of intestinal obstruction. Plain abdominal X-rays are suggestive of mechanical bowel obstruction which was present in our case. A paraduodenal hernia may be demonstrated by an upper gastrointestinal series performed during a period of acute symptoms. Barium contrast study demonstrates sac-like mass of mildly dilated jejunal loops, left of the ligament of Treitz with mass effect causing displacement of the greater curvature and posterior wall of the stomach [37 ]. Ultrasonography in internal hernia shows hetergenous echoic abdominal mass with presence of changing cystic or tubular internal components and a surrounding the membrane [38]. On computed tomography (CT) scan, the findings are very non-specific. Small bowel is seen enveloped in a thin membrane and may be suggestive of peritoneal encapsulation [20, 23, 39]. The following findings are seen on CT scan in left paraduodenal hernia [27, 40, 41]:

(a) A focal cluster of small bowel loops positioned abnormally between the pancreatic body or tail and the stomach lying to the left side of ligament of Treitz or behind the descending colon and distal transverse colon.

(b) Bowel loops proximal and within hernial sac show dilatation with air fluid levels.

(c) Narrowing of efferent loops of bowel.

(d) Mass effect causing displacement and indentation of posterior wall of stomach, inferior displacement of duodenojejunal junction and transverse colon and medial displacement of the descending colon.

(e) Inferior mesenteric vein and ascending left colic artery being displaced anterolaterally or upward.

(f) Normal vascular relationship, although there might be mild displacement caused by the herniated loops.

(g) Mesenteric vessels that supply the herniated small bowel segments show crowding at the entrance of hernial sac and the vessels in hernial sac are engorged. (h) Normal vascular relationship of superior mesenteric artery and vein are usually maintained.

Congenital adhesions involve surgical release of adhesions and bands. Treatment of peritoneal encapsulation involves the total removal of the anomalous membrane and release of both openings. Bowel resection may be necessary if the membrane cannot be stripped atraumatically or if obvious gangrene of the bowel is present. There is no reoperation reported in literature after dividing the encasing membrane in peritoneal encapsulation [4].

Surgical treatment of left paraduodenal hernia follows the basic principles of hernia surgery: reduction of the contents, restoration of normal anatomy and repair of the defect $[33,42]$. A retroperitonealization of inferior mesenteric vein involves retroperitonealization of vein after release of congenital adhesions.

\section{CONCLUSION}

Occurrence of paraduodenal hernia, peritoneal encapsulation and congenital adhesions leading retroperitonealization of inferior mesenteric vein in the same patient is rare. Left paraduodenal hernia rarely presents as an acute abdomen. Occurring of three abnormal anatomical structures must have had a congenital origin as the patient had no predisposing factors for the development of these congenital anamolies.

$* * * * * * * * *$

\section{Author Contributions}

Imtiaz Wani - Substantial contributions to conception and design, Acquisition of data, Analysis and interpretation of data, Drafting the article, Revising it critically for important intellectual content, Final approval of the version to be published

Khursheed A Wani - Substantial contributions to conception and design, Acquisition of data, Analysis and interpretation of data, Drafting the article, Revising it critically for important intellectual content, Final approval of the version to be published

Muneer Wani - Substantial contributions to conception and design, Acquisition of data, Analysis and interpretation of data, Drafting the article, Revising it critically for important intellectual content, Final approval of the version to be published

Gulzar Bhat - Substantial contributions to conception and design, Acquisition of data, Analysis and interpretation of data, Drafting the article, Revising it critically for important intellectual content, Final approval of the version to be published

Mubashir Shah - Substantial contributions to conception and design, Acquisition of data, Analysis and interpretation of data, Drafting the article, Revising it critically for important intellectual content, Final approval of the version to be published 


\section{Guarantor}

The corresponding author is the guarantor of submission.

\section{Conflict of Interest}

Authors declare no conflict of interest.

\section{Copyright}

(C) Imtiaz Wani et al. 2013; This article is distributed under the terms of Creative Commons Attribution 3.0 License which permits unrestricted use, distribution and reproduction in any means provided the original authors and original publisher are properly credited. (Please see www.ijcasereportsandimages.com /copyright-policy.php for more information.)

\section{REFERENCES}

1. Cleland. On an Abnormal Arrangement of the Peritoneum, with Remarks on the Development of the Mesocolon. J Anat Physiol 1868;2(2):201-6.

2. Gokcora IH, Gulec S, Ozdamar S. Peritoneal encapsulation and abdominal cocoon. T J Research Med Scl 1988;6:25-8.

3. Adedeji OA, McAdam WA. Small bowel obstruction due to encapsulation and abnormal artery. Postgrad Med J 1994;70(820):132-3.

4. Al-Taan OS, Evans MD, Shami JA. An asymptomatic case of peritoneal encapsulation: case report and review of the literature. Cases Journal 2010;3:13.

5. Arora PK, Narang R, Sethna KS, Gupta D. Peritoneal encapsulation of small bowel--(a case report). Peritoneaof small bowel--(a case report). J Postgrad Med 1989;35(4):219-1.

6. Thorlakson PH, Monie IW, Thorlakson TK. Anomalous peritoneal encapsulation of the small intestine; a report of three cases. Br J Surg 1953 Mar;40(163):490-3.

7. Naraynsingh V, Maharaj D, Singh M, Ramdass MJ. Peritoneal encapsulation: a preoperative diagnosis is possible. Postgrad Med J 2001;77(913):725-6.

8. Sherigar JM, McFall B, Wali J. Peritoneal encapsulation: presenting as small bowel obstruction in an elderly woman. Ulster Med J 2007 January;76(1):42-4.

9. Virich G, Davies W. A massive left paraduodenal fossa hernia as an unusual cause of small bowel obstruction. Ann R Coll Surg Engl 2010;92(4):W7-9.

10. Habib E, Elhadad A. [Small bowel obstruction by a congenital band in 16 adults]. Ann Chir 2003;128(2):94-7.

11. Akgur FM, Tanyel FC, Buyukpamukcu N, Hicsonmez A. Anomalous congenital bands causing intestinal obstruction in children. $J$ Pediatr Surg 1992;27(4):471-3.

12. Yun MY, Choi YM, Choi SK, Kim SJ, Ahn SI, Kim KR. Left paraduodenal hernia presenting with atypical symptoms. Yonsei Med J 2010 Sep;51(5):787-9.

13. Amodio PM, Alberti A, Bigonzoni E, Piciollo M, Fortunati T, Alberti D. [Left paraduodenal hernia: a case report and review of the literature]. Chir Ital 2008;60(5):721-4.
14. Dimitrios C, George AA, Dimosthenis Z, Nikolaos X. Intestinal obstruction due to an anomalous congenital band. Saudi J Gastroenterol 2008;14(1):36-7.

15. Freund H, Berlatzky Y. Small paraduodenal hernias. Arch Surg 1977;112(10):1180-3.

16. Okobia MN, Osime U, Evbuomwan I. Congenital peritoneal encapsulation of small intestine: a case report. West Afr J Med 2001;20(3):279-81.

17. Mesas Burgos C, Lundegårdh G, Loogna $P$. Laparoscopic Gastric Bypass in a Patient with Peritoneal Encapsulation and Malrotation of the Intestine. J Clinic Case Reports 2011;1:101.

18. Walsh TN, Russell J. Peritoneal encapsulation of the small bowel. Br J Surg 1988;75(11):1148.

19. Mordehai J, Kleiner O, Kirshtein B, Barki Y, Mares AJ. Peritoneal encapsulation: a rare cause of bowel obstruction in children. $\mathrm{J}$ Pediatr Surg 2001;36(7):1059-61.

20. Huddy SP, Bailey ME. Small bowel obstruction due to peritoneal encapsulation. $\mathrm{Br} \quad \mathrm{J} \quad \mathrm{Surg}$ 1988;75(3):262.

21. Silva MB Jr. Connolly MM, Burford-Foggs A, Flinn WR. Acute aortic occlusion as a result of extrinsic compression from peritoneal encapsulation. J Vasc Surg 1992;16(2):286-9.

22. Tsunoda T, Mochinaga N, Eto T, Furui J, Tomioka T, Takahara H. Sclerosing encapsulating peritonitis combined with peritoneal encapsulation. Arch Surg 1993;128(3):353-5.

23. Ince V, Dirican A, Yilmaz M, Barut B, Ersan V, Yilmaz S. Peritoneal encapsulation in a patient with incomplete situs inversus. J Coll Physicians Surg Pak 2012;22(10):659-60.

24. Freud E, Zer M. Left Paraduodenal Hernia: Embryological and Surgical Considerations. Dig Surg 1992;9:169-71.

25. Fan HP, Yang AD, Chang YJ, Juan CW, Wu HP. Clinical spectrum of internal hernia: a surgical emergency. Surg Today 2008;38(10):899-904.

26. Papaziogas B, Lazaridis C, Souparis A, et al. Idiopathic Hypertrophic Pyloric Stenosis Combined with Left Paraduodenal Hernia in an Adult. Med Princ Pract 2007;16(2):151-4.

27. Peltier J, Le Gars D, Page C, Yzet T, Laude M. The duodenal fossae: antomic study and clinical correlations. Surg Radiol Anat 2005;27(4):303-7.

28. Willwerth BM, Zollinger RM Jr, Izant RJ Jr. Congenital mesocolic (paraduodenal) hernia. Embryologic basis of repair. Am $J$ Surg 1974;128(3):358-61.

29. Khalaileh A, Schlager A, Bala $M$, et al. Left laparoscopic paraduodenal hernia repair. Surg Endosc 2010;24(6):1486-9.

30. Kandpal H, Sharma R, Saluja S, Sahni P, Vashisht S. Combined transmesocolic and left paraduodenal hernia: barium, CT and MRI features. Abdom Imaging 2007;32(2):224-7.

31. Newsom BD, Kukora JS. Congenital and acquired internal hernias; unusual causes of small bowel obstruction. Am J Surg 1986;152(3):279-85.

32. Sen M, Inan A, Dener C, Bozer M. [Paraduodenal internal hernias: clinical analysis of two cases]. Ulus Travma Acil Cerrahi Derg 2007;13(3):232-6.

33. Rollins MD, Glasgrow RE. Left paraduodenal hernia. J Am Coll Surg 2004;198(3):492-3. 
34. Kondi ES, Gallitano AL, Katz SJ. A new variant of intra-abdominal hernia. Ann Surg 1975 Apr;181(4):442-6.

35. Ellis $H$. The magnitude of adhesion related problems. Ann Chir Gynaecol 1998;87(1):9-11.

36. PERRY JF Jr, SMITH GA, YONEHIRO EG. Intestinal obstruction caused by adhesions; a review of 388 cases. Ann Surg 1955;142(5):810-6.

37. Blachar A, Federle MP. Internal hernia: an increasingly common cause of small bowel obstruction. Semin Ultrasound CT MRI 2002;23(2):174-83.

38. Wachsberg RH, Helnek TG, Merton DA. Intral abdomonal hernia:diagnosis with ultrasonography. Can Assoc Radiol J 1994;45(3):223-4.
39. Chew MH, Sophian Hadi I, Chan G, Ong HS, Wong WK. A problem encapsulated: the rare peritoneal encapsulation syndrome. Singapore Med J 2006;47(9):808-10.

40. Manji R, Warnock GL. Left paraduodenal hernia: an unusual cause of small-bowel obstruction. Can J Surg 2001;44(6):455-7.

41. Okino $\mathrm{Y}$, Kiyosue $\mathrm{H}$, Mori $\mathrm{H}$, et al. Root of small bowel mesentery: correlative anatomy and CT features of pathological conditions. Radiographics 2001;21(6):1475-90.

42. Brigham RA, Fallon WF, Saunders JR, Harmon JW, d'Avis JC. Paraduodenal hernia: diagnosis and surgical management. Surgery 1984;96(3):498-502.
Access full text article on other devices

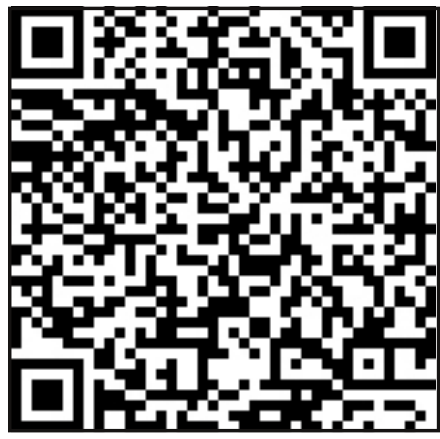

Access PDF of article on other devices

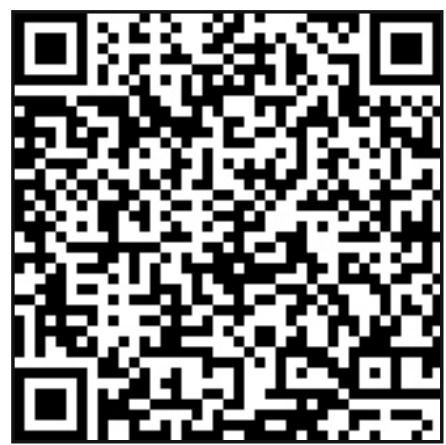

